\title{
PROCESOS POLÍTICOS EN AMÉRICA LATINA: \\ UNA PERSPECTIVA SOBRE LAFORMA DE VER LA DEMOCRACIA DE LOS LATINOAMERICANOS
}

\author{
Maximiliano Korstanje
}

\begin{abstract}
RESUMO
O presente artigo trata das percepções dos latino-americanos a respeito da democracia como figura de ordem politica. Os resultados obtidos permitem - indicando, salvo exceções, uma queda generalizada da confiança dos latino-americanos em relação à democracia - fazer uma breve comparação com os hábitos dos estadunidenses e dos europeus. O ponto em questão está na tensão teórica entre a democracia em seu sentido mais procedimental e em seu sentido mais estrutural.
\end{abstract}

PALAVRAS-CHAVE: democracia; América Latina; confiança política; indiferença.

\section{INTRODUCCION}

El término democracia deriva del griego "demos" y fue inculcado entre el 500 a. C. y el 250 a. C. y (etimológicamente) significa "gobierno del pueblo". Sin embargo, sus alcances (en esa época) eran restringidos sólo a los ciudadanos.

Actualmente, la palabra puede ser analizada desde dos perspectivas diferentes. La primera, procedimental, se vincula a la forma de votación por la cual se imponen los gobernantes y por las cuales toman las decisiones políticas.

La segunda, netamente estructural, se basa en las características ideales (participación, libertad, igualdad entre otras) que una sociedad debe cumplir para el buen convivir (lo socialmente esperable de la democracia) (ACTON INSTITUTE, s/d).

El concepto al cual apunta este trabajo es una síntesis tanto del abordaje procedimental como estructural y puede resumirse en una pregunta. ¿Cómo perciben los latinoamericanos a la democracia?

Sin embargo, para poder continuar desarrollando el tema de una manera más acabada se necesitan otras preguntas que vayan dando forma a la investigación. Por ejemplo, ¿qué relación existe entre la percepción latinoamericana, europea y estadounidense sobre su sistema democrático?, ¿existe diferencia o similitud?, ¿por qué?, ¿es la indiferencia hacia la democracia una cuestión que excede a los países latinoamericanos o no?
Los objetivos del trabajo apuntan a describir las diferentes percepciones que latinoamericanos tienen sobre la democracia, establecer una comparación entre esa percepción con respecto a los estadounidenses y europeos, y por último explicar la relación que existe entre eficacia y legitimidad dentro del sistema democrático.

La hipótesis sobre la cual se parte es que los latinoamericanos poseen una mala imagen de la democracia debido al poco uso que han hecho de ella, mientras que los europeos y estadounidenses (mayoritariamente) poseen una buena imagen tras haberla ejercido por lapsos de tiempo más prolongados.

Desde un punto de vista teorético se analizan diversos autores y los aportes que estos han podido brindar al estudio del fenómeno. Sin embargo, por una cuestión de tamaño no se ha incluido a todos, sino más bien a aquellos que se consideran los más destacados - en el marco de la sociología política.

Luego, desde un abordaje empírico se utilizan (como fuentes públicas) los informes de prensa correspondientes la Corporación Latinobarómetro, que van desde el año 1995 al 2006 inclusive. En estos informes se encuentran detalladas todas las variables que hacen a la percepción que los encuestados tienen de su organización política y los procesos democráticos que de ella derivan. Asimismo, se comparan esos resultados con (otros) estudios empíricos aplicados en Estados Unidos y Europa.

Rev. Sociol. Polít., Curitiba, 29, p. 187-202, nov. 2007 
Si bien la percepción de lo que significa la democracia en la muestra utilizada en Latinoamérica tiene similitudes con Estados Unidos o con Europa, existen ciertos componentes culturales que la distinguen. Indagar y describir los motivos que subyacen en esa construcción es el objetivo póstumo de la presente investigación. Pero para ello, se debe (inicialmente) comenzar a cuestionar que entiende la sociología y la ciencia política por democracia.

Obviamente, que cada informe de prensa trabajó con indicadores diferentes dependiendo del año, lo cual complica su propia operalización; de todos modos, existe una coincidencia en los contenidos que cada uno fue desarrollando desde 1995 a 2006 y una correlación histórica que puede estudiarse.

Desde el momento en que la democracia está inserta en un amplio sistema que no sólo se refiere al mundo político, sino que también es sensible a distintos hechos del mundo económico y social, es que se decidió incluir en este trabajo categorías que no necesariamente hacen a la vida democrática stricto sensu.

Las variables utilizadas fueron divididas en tres categorías: a) los problemas más importantes de los encuestados, b) la percepción sobre la distribución del ingreso, y c) percepción de la democracia e instituciones

Como marco referencial, se ha escogido los trabajos de dos autores de renombre en la sociología política; Jose Luis de Imaz con su obra Sobre la Identidad Iberoamericana, y de Martin Lipset, El hombre Político.

Ambos enfoques pretenden responder, de una $\mathrm{u}$ otra manera, a los interrogantes anteriormente planteados.

II. ¿QUÉ SE ENTIENDE POR DEMOCRACIA SEGÚN LALITERATURA SOCIOLÓGICA?

"Teóricamente hay muchas democracias posibles, es decir, concebibles lógicamente, pero no hay muchas posibles históricamente. Si el significado actual de democracia proviene de su significado griego y tiene poca semejanza con un pueblo que se autogobierna, la transformación refleja los fracasos históricamente reiterados de tal autogobierno" (Sartori, 1988, p. 330).

Para Robert Dahl, la democracia moderna se remonta a cuatro fuentes principales: la Grecia clásica, la tradición republicana en el imperio romano, la idea y las instituciones del gobierno representativo, y la lógica de la igualdad política. Sin embargo, esta forma de organización política ya desde sus orígenes demostraba algunas limitaciones. En primer lugar, la vida política era en Atenas dura y no muy diferente a la de otros pueblos que no practicaban la democracia; segundo, lejos de lo que se pensaba sólo una minoría asistía a las asambleas legislativas (DAHL, 1991, p. 35)

La tensión entre la democracia "ideal" y "real" continúa y está reflejada en la mayoría de la literatura que se ocupa del tema. En este sentido, Chambers y Salisbury señalan "el problema central emana de una manifiesta sensación contemporánea de discrepancia entre la idea y la práctica. Con más precisión: comprende la percepción de un vacío entre el exaltado cuadro de la democracia que hemos heredado de nuestra tradición occidental, por una parte, y la realidad de la democracia tal como la vemos en la actualidad por otra" (CHAMBERS \& SALISBURY, 1967, p. 3)

Norberto Bobbio, plantea desde la perspectiva teórica un análogo problema. El punto en cuestión es resumido con una pregunta, ¿gobierno de hombres o gobierno de las leyes?; en efecto, lo que Bobbio analiza no es el modelo de gobierno, en este caso la democracia en sí, sino la forma en que se gobierna; es decir, las diferentes formas que adquiere la democracia en los diferentes contextos socio-culturales en donde se la aplica (BOBBIO, 1996, p. 167). Este debate es parte de aquel que a principios del treinta entablaran Hans Kelsen y los positivistas en oposición a la tesis del decisionismo schmitiano (DOTTI, 2000; KELSEN, 2005)

Para Alain Tourraine, la democracia debe ser comprendida como un constructo teórico; como tal es ajena a los modelos de gobierno. Sin embargo, existe una idea implícita tras el concepto de democracia. Tourraine, sostiene que la democracia se construye sólo cuando todos los derechos del hombre están garantizados. De allí se desprenden tres dimensiones claves que sostienen al régimen democrático: a) respeto a los derechos fundamentales, b) representatividad de los gobernantes y ciudadanía, y c) limitación de poderes de la élite política. En las democracias occidentales es extraño poder observar que estos elementos se den con igual fuerza. 
Desde este índice analítico el autor traza una tipología a las que denomina "las tres democracias". Cada tipo democrático se encuentra más presente en ciertos tipos de sociedades y menos en otras. Por ejemplo, Gran Bretaña puede considerarse una sociedad donde el respeto por los derechos individuales se halla en sus bases sociales. Por el contrario, Estados Unidos es el país donde mayor importancia se le da a la ciudadanía y por lo tanto alcanza el segundo supuesto; finalmente en la democracia francesa es donde los poderes se encuentran en una posición de equilibrio en cuanto a su fuerza (TOURRAINE, 1995, p. 46).

Sin embargo, el problema parece ser mucho más profundo que la relación que existe entre el poder con el régimen democrático. Por un lado, existen elementos históricos que refuerzan los modos democráticos (SARTORI, 1988). Pero por el otro, también la democracia ha sabido influir sobre las costumbres culturales de los pueblos.

Sin ir más lejos, Tocqueville advierte "la democracia no constituye un fuerte lazo de unión entre los hombres, pero facilita sus relaciones cotidianas [...] en un país extranjero, dos americanos se hacen amigos inmediatamente por el sólo hecho de ser americanos. No hay prejuicio que los aleje y la comunidad de patria los atrae. A dos ingleses no les basta tener la misma sangre, es preciso que les una la misma clase social" (TOCQUEVILLE, 1993, p. 146).

Lo que el autor intenta explicar es que la estratificación social como variable dependiente, en ocasiones también limita los márgenes de la democracia. No obstante, recursivamente las acciones individuales terminan legitimando el régimen político acorde a sus propios intereses y necesidades de grupo.

Uno de los autores que se pueden considerar pre-modernos que se ocupó, casi sin quererlo, de la democracia, fue Nicholas Maquiavelo. En el Príncipe, el autor descubre a la masa como un ente sobre la cual los gobernantes podían ejercer poder y autoridad a un costo relativamente bajo. En efecto, a contrario de la nobleza cuya ambición era desmedida (pensaba Maquiavelo), el pueblo solamente deseaba seguridad. En vez de confrontar directamente con los nobles en luchas intestinas, el gobernante debía servirse de la lealtad popular.
Casi sin proponérselo, Maquiavelo sostenía que el juego político entre los príncipes debía ser regulado por las necesidades populares. El antagonismo de intereses sostenía el régimen y permitía que la lucha política se mantuviera por canales pacíficos $^{1}$. ¿Un precursor de la democracia o del clientelismo político? o ¿ambas (MAQUIAVELO, 2006)?

En la actualidad, la democracia se ha expandido por casi la mayoría de los estados occidentales. Los derechos políticos han sido ampliados y en mayor o menor medida los gobernantes se ocupan de satisfacer las necesidades de sus ciudadanos. Sin embargo, paradójicamente cada vez más gran cantidad de personas ven con mayor indiferencia la participación política.

Sheldon Wolin advierte "nos hallamos, al parecer en una época en que el individuo busca de modo creciente sus satisfacciones políticas fuera del ámbito tradicional de la actividad política" (WOLIN, 1973, p. 378).

Dryzek y Berejikian (1993) realizaron un estudio en Estados Unidos sobre la percepción que los ciudadanos tenían de la democracia. Consultando a personas comunes, líderes sindicales, activistas, políticos y escritores, llegaron a concluir en (de 64 enunciados) que existen cuatro discursos principales en los actores consultados: Republicanismo conforme, donde la democracia se considera la mejor forma de gobierno y de vida, el gobierno no es un adversario sino un aliado; conservadurismo diferencial, la democracia no es algo deseable o indeseable sino algo difícil de definir, el egoísmo es inherente a la política sin importar el régimen; Populismo desafecto, ciertas elites empresarias y financieras han tomado el poder y movilizan todos sus recursos a su bienestar personal. Mientras los ciudadanos oprimidos no se revelen en contra de ese poder, la igualdad política seguirá siendo una mera utopía; Liberalismo privado, la democracia no es valiosa ya que trae consigo a tipos de gobiernos poco igualitarios, es la vida privada lo que es realmente importante y no la participación pública. El

\footnotetext{
${ }^{1}$ Obviamente, Maquiavelo estaba interesado por el análisis del poder y no de la democracia en sí, pero sus abordajes (geniales para la época) sirvieron de base para otros ilustrados políticos tales como Hobbes, Locke, Bentham, Montesquieu, Rousseau o Tocqueville mismo.
} 
accionar del gobierno debe ser reducido y no interferir en el mercado de capitales (idem, p. 4860; GOODIN, 2003, p. 147-150).

Estas cuatro formas de ver y vivir la democracia coexisten en la misma sociedad, sin embargo los intereses de grupo que persiguen son totalmente encontrados. En cierta forma, esto presupone que (entonces) la representatividad democrática no está dada por la institución en sí, sino más bien por los intereses de cada grupo. ¿Es quizás la democracia una lucha constante de discursos en el mejor sentido hobbesiano?

Es posible, mas es pertinente aclarar que las elecciones democráticas funcionan como un ejercicio de proyección, donde los candidatos enarbolan características que el propio votante reconoce adolecer en su persona. Como sus representantes, los gobernantes siguen principios de honestidad, justicia, rectitud y benevolencia (Brennan apud GOODIN, 2003, p. 323). Sin embargo, tarde o temprano los ciudadanos terminan dándose cuenta que sus líderes no sólo no poseen las cualidades imaginadas sino que están sujetos a sus mismos vicios y debilidades (y sino más deplorables) (BUCHANAN, 1979).

Por lo general, existe una "creencia social" a considerar que cuanto mayor es la participación en los procesos de elección procedimentales que hacen a la "democracia representativa", menores serán los efectos indeseados (LAPORTA, 1989). No obstante, paradójicamente esa misma participación parece disminuir a medida que aumenta el tamaño del grupo. En una sociedad, pocos son aquellos que se interesan por asistir a la promulgación de las leyes en los espacios legislativos. Así la opinión pública queda sujeta a la acción de otros intermediarios (HABERMAS, 1981).

Algunos estudios de campo sugieren que la estratificación social es un aspecto a tener en cuenta cuando se evalúa la tendencia al autoritarismo. Janowitz y Marvick (1953, p. 195) demostraron que las "clases" menos privilegiadas tienen un nivel de intolerancia más acentuado que el resto. Otros trabajos señalan, que las "clases bajas" muestran una mayor vulnerabilidad de ser atraídas por los movimientos extremistas sean estos políticos o religiosos (NICHOLAS, 1950; GOGUEL, 1953).

Esta participación en movimientos no demo- cráticos se explica, según el psicólogo Hadley Cantril, a través de su tesis de la sugestionabilidad típica de las personas de un status bajo. Según este autor, la falta de un adecuado marco de referencia o la posesión de uno rígido son unas de las características que hacen a los sujetos de educación limitada. Ante cualquier hecho externo, un sujeto con un marco referencial poco flexible demostrará una inclinación a elevar el hecho en forma absoluta, estableciendo categorías bipolares (en cierto sentido, impermeables a la interacción con el otro) (CANTRIL, 1941).

Bernstein parece llegar a una conclusión análoga al concluir que la socialización de las clases medias apoya una habilidad para el desarrollo de una metodología orientada a la cadena de medios y fines, mientras que las clases "bajas" se conducen meditante un código "restringido" en ocasiones arbitrario (BERNSTEIN, 1989).

En esta misma línea, Lipset señala “este énfasis en lo inmediatamente perceptible y la preocupación por lo personal y lo concreto forman parte inseparable de la perspectiva restringida y de la incapacidad para percibir las posibilidades y consecuencias complejas de las acciones que se traducen a menudo en una disposición general para apoyar los movimientos políticos y religiosos extremistas, $y$ un nivel generalmente bajo de liberalismo en las cuestiones no económicas" (LIPSET, 1988, p. 102).

En similitud con Lipset, David Easton habla de un apoyo difuso y un apoyo específico con respecto al orden político. Siguiendo al estructural funcionalismo, el autor establece que en la vida política la "retroalimentación" es un elemento clave para la autorregulación del sistema. Particularmente, la concreción de objetivos planteados perpetua estructuralmente la organización política y preserva su equilibrio (EASTON, 1965).

Sin embargo, no necesariamente las "clases bajas" se vinculen a los movimientos autoritarios por atributos intrínsecos sino que en ocasiones adhieren a ellos en contraposición a las ideologías enarboladas por las clases privilegiadas. De esa manera, en sociedades donde las clases más acomodadas abracen ideologías autoritarias, los estratos inferiores se esforzarán por defender la libertad y resaltar sus derechos constitucionales, mientras que en sociedades donde las élites sean liberales los estratos bajos mostrarán una tendencia mayor al autoritarismo. 
Otro de los errores comunes en los que han caído muchos pensadores es en afirmar que democracia es un sinónimo de libertad. En su análisis de la sociedad de consumo americana, el frankfurtiano Erich Fromm (1965) se encargó de brindar elementos suficientes para refutar o cuestionar, aunque más no sea, esa idea en forma parcial.

Diderot y D'Alembert definen a la democracia como "una de las formas simples de gobierno, en la cual el pueblo, como cuerpo único, posee toda la soberanía. Toda República en la que la soberanía reside en las manos del pueblo es una democracia". No obstante, ya en ese entonces Diderot, aunque la consideraba como el mejor régimen posible, conocía de sus limitaciones. "Aunque no pienso que la democracia sea la forma más cómoda y estable de gobierno, y aunque estoy persuadido de que es desventajosa para los grandes Estados, la creo no obstante, una de las formas más antiguas de las naciones que han seguido esta máxima equitativa" (DIDEROT \& D'ALEMBERT, 1986, p. 22).

Desde el punto de vista de estos autores, para que la democracia sea sustentable deben presentarse cuatro condiciones: a) las reuniones de las asambleas deben estar limitadas en tiempo y espacio, b) la pluralidad del sufragio debe ser considerada en relación a todo el cuerpo social, c) la existencia de magistrados encargados de convocar a las asambleas en casos extraordinarios, d) el pueblo debe estar dividido en clases ( sic), varias si es posible.

Estas ideas (de por sí) muestran algunas limitaciones que se deben aclarar antes de proseguir; por un lado la misma división de la sociedad en estratos fomenta la "aristocracia", enemiga acérrima de la democracia. Por el otro, el mismo Diderot acepta (de confeso) que la democracia es desventajosa en los grandes estados y por lo pronto poco estable.

En efecto, cualquier reflexión sobre los alcances y limitaciones de la democracia conllevan (implícitamente) un problema de difícil solución. Desde un punto de vista estructural, la democracia ha surgido como un concepto teórico, abstracto e ideal que muchas veces no se condice con su aplicación práctica. Los ideales de igualdad, fraternidad y participación son muchas veces impuestos a través de medidas coactivas que se alejan de la libertad. En este punto, existe una tensión inherente a esta definición. Si por un lado, la democracia trae pluralidad de intereses, igualdad y cooperación por el otro no es menos cierta que ocasionalmente conlleva conflicto, coacción y autoritarismo demagógico.

No obstante, esta incompatibilidad es resuelta desde el marco procedimental a través del régimen de la República (heredado de las ideas romanas y griegas), el cual establece que la democracia es una construcción humana por tanto perfectible, y su aplicación debe llevarse a cabo a través de la limitación de poderes del gobernante (sean estos a través de una votación o la división de poderes). Desde este punto de análisis, la República como sistema político garantiza la participación ciudadana mediante el uso coercitivo de la fuerza por parte del Estado. Sin embargo, cuando un régimen pierde legitimidad, es probable que en igual proporción pierda eficacia y caiga.

Siendo así, no es complicado imaginar que algunos gobernantes se vean influenciados a corromper las mismas normas procesales para la concreción de los objetivos propuestos. Algo que el sociólogo estadounidense Robert Merton llamó hace mucho tiempo "anomia por innovación" (MERTON, 1965). Paradójicamente, la élite política conserva la legitimidad del orden público en detrimento del marco democrático (Procedimental).

En forma inversa, cuando el gobernante respeta las normas en detrimento de sus objetivos, pierde legitimidad y en algunos casos el mismo sistema democrático se ve seriamente perjudicado.

Este problema ha sido planteado por muchos de los sociólogos y politólogos que se encargaron de analizar el tema. Es en parte, la misma paradoja teórica la que lleva a interpretar mal los datos de campo. Esta exposición trae varios interrogantes que hasta ahora no se han planteado. ¿Los latinoamericanos tienen una cultura democrática diferente a la de otras sociedades?, ¿el problema de la eficacia atenta realmente contra la legitimidad del orden democrático?, ¿es la anomia por innovación un característica cultural de los latinoamericanos o se encuentran en otras sociedades también?

\section{LOS PROCESOS DEMOCRÁTICOS EN LA AMÉRICAHISPANA.}

El politólogo argentino Jose Luis de Imaz explica a través de la "transculturación" que se llevó 
a cabo con la colonización española en América, parte de las formas y actitudes que han adquirido el ciudadano para concebir la política en América Latina.

Originariamente, el español que piso América reconocía a sus semejantes mediante un código honorífico-estamental. Advierte De Imaz, "ese código que admitía el acceso a la riqueza tras la guerra (aunque fuera por la rapiña pero en ocasión de guerra) relegaba esas ansias a sus roles instrumentales [...] el discurso del conquistador, seguía un derrotero muy diferente al de un racionalista o al de un moderno contemporáneo: como estaba construido sobre absolutos, partía de la causa final en el sentido escolástico del vocablo" (IMAZ, 1984, p. 71).

Bajo estas líneas, comienza a gestarse la percepción política de los pueblos hispano- americanos. Por un lado, la tendencia a exacerbar los ideales por sobre los métodos; hecho que llevó a concebir a los procesos democráticos como ideales organizativos con arreglo a los resultados de gestión. Por otro lado, un código militar que comprendía "al otro" bajo la lógica amigo-enemigo.

A todo esto se suma el hecho que en 1760, el monarca español, Carlos III realiza un conjunto de reformas con el fin de mantener su hegemonía dentro de las "Américas". Estas reformas implicaban la reorganización de sus fuerzas armadas dándole cabida - en ellas - a todo aquel nacido dentro de territorio español; de este modo ingresaron al ejercito español un sinnúmero criollos para quienes la carrera militar significaba el único modo de movilidad social en ese entonces. Paradójicamente, esta medida provoca una creciente militarización en América Latina que encuentra su punto máximo en la declaración de independencia. En cierta forma, la intención de Carlos III fue evitar la disgregación de sus colonias pero sus medidas no encuentran sino un resultado adverso (LIEUWEN, 1960, p. 34-50).

El siglo XIX encuentra a España empobrecida en lo económico y financiero y debilitada en el orden político interno. Sus posesiones en América no representaban uno de sus intereses más prioritarios. Fue así, que los nuevos Estados latinoamericanos se vieron en una situación inusual; por un lado no tuvieron un marco de referencia que pudiera regular sus relaciones, y el otro heredaron las fronteras territoriales que se habían establecido durante el dominio ibérico. En algún punto, comenzaron las primeras revoluciones militares internas.

En su obra Los que mandan, Imaz toma como objeto de estudio a los militares argentinos entre los períodos 1936-1961, y el papel auto-percibido de sus funciones para con la sociedad. Existen ciertas cuestiones, que hacen que algunos grupos excedan sus roles constitucionalmente preestablecidos. Imaz toma tres niveles de análisis para el accionar de las fuerzas armadas, a) el militarismo: fuerza destinada a conquistar todos los resortes del país con miras bélicas hacia el exterior, b) el pretorianismo, instaurado por las legiones romanas, c) el estado totalitario, algo similar a los poderes ejercidos por el III Reich durante la II Guerra.

Imaz, descarta que todos estos modelos sean aplicables para el caso argentino. En uno de sus pasajes, el autor advierte "En la Argentina, la intervención de las fuerzas armadas en la vida política ha sido siempre una consecuencia de la crisis de legitimidad que periódicamente han sacudido al país, o de circunstanciales vacíos de poder" (IMAZ, 1964, p.51). Así, los militares como cuadros formados bajo lemas consignados a la eficiencia, han tomado de por sí el deber (según ellos) de garantizar y proteger a la nación ( cuando la circunstancias (así) lo requieren.

En su Aclaración para civiles y epílogo para militares, el profesor Imaz señala "no siempre es fácil superar las barreras de comunicación que separan a los civiles de los militares. Pero este problema no es sólo argentino, sino universal [...] los militares, por ejemplo, sobrevaloran la eficacia. Siempre que provenga de la unidad de conducción, de la organización y perfecta articulación de los cuadros [...] de ahí que la ineficacia de los civiles - la ineficacia de los políticos peñados en discusiones estériles referidas siempre a hechos del pasado - los sobrecoja" (idem, p. 75).

Como cualquier organización, las fuerzas armadas poseen funciones manifiestas que obedecen a las aquellas prefijadas por la carta magna, y funciones latentes, atribuciones auto-percibas tal como considerarse los guardianes del bienestar de la nación.

Con respecto al desempeño histórico de las fuerzas armadas argentinas en la vida cívica del país, el politólogo concluye "en cada caso, el comportamiento militar estuvo determinado por 
una ideología especifica - cambiante según los casos -, sino por la continuidad de una misma e idéntica actitud. Hay dos constantes reguladoras del comportamiento militar: el pleno convencimiento de que en cuanto salvaguardias del patriotismo deben salir en su defensa cada vez que lo crean en peligro" (IMAZ, 1984, p. 78).

Lipset (1988), por el contrario, hace un planteamiento enfocado desde otro ángulo, pero análogamente similar al del profesor Imaz. Para el autor, toda organización se basa en dos pilares fundamentales: legitimidad, la cual hace referencia a la aceptabilidad que tiene el régimen que mantiene cohesionada a la organización, y en segundo lugar la eficacia, que hace referencia a la concreción de los objetivos planteados por toda la comunidad. (El equilibrio, entre legitimidad y eficacia hacen al orden organizacional.)
Max Weber (1999, p. 39) suponía que la democracia era una consecuencia de los procesos de industrialización capitalista. El profesor Lipset utiliza esa idea, y la lleva al campo de los datos empíricos $^{2}$. Por un lado, el autor establece cuatro categorías en referencia a la democracia como variable (independiente), democracias estables en naciones europeas y de habla inglesa, democracias inestables y dictaduras europeas, democracias y dictaduras inestables en América Latina y dictaduras estables en América Latina.

Por el otro, estas cuatro tipologías son comparadas con cuatro indicadores que hacen referencia a: ingreso per capita, indice de industrialización, indice de educación, e índices de urbanización. El esfuerzo de Lipset, por aunar las vidas políticas de por lo menos 49 países se resume a continuación para una lectura más detallada 3 .

\section{TABLA 1 - DISTRIBUCIÓN DE INDICADORES POR TIPO DEMOCRÁTICO}

\begin{tabular}{|l|c|c|c|c|}
\hline & & HOMBRES & PORCENTAJE & PORCENTAJE \\
\hline Montos en Dólares Americanos & Ingreso & Agricultura & Letrados & Ciudades \\
Tipo de Democracia & & & & \\
Democracia estable Europeas & $\$ 695,00$ & 21 & $96 \%$ & $43 \%$ \\
Democracia inestable Europeas & $\$ 308,00$ & 41 & $85 \%$ & $24 \%$ \\
Democ. y Dictadur. Inest. & & & & $28 \%$ \\
Latinoamericana & $\$ 171,00$ & 52 & $46 \%$ & $17 \%$ \\
Dictaduras Estables latinoamericana & $\$ 119,00$ & 67 & & \\
\hline
\end{tabular}

FUENTE: Lipset (1988, p. 45).

De mayor a menor, puede observarse claramente que los mayores ingresos se corresponden con las sociedades que viven en Democracia estable (\$695) o inestable (\$308) europeas, mientras que las democracias inestables latinoamericanas y dictaduras muestran los menores ingresos promedio. Asimismo, Las democracias europeas estables e inestables tienen un cantidad de hombres promedio destinados a la agricultura mucho menor que aquellas democracias inestables y dictaduras latinoamericanas. Los porcentajes de letrados y ciudades siguen una dinámica similar. En las democracias estables europeas el $96 \%$ son letrados, mientras este porcentaje baja al $85 \%$ en las democracias inestables europeas, a $74 \%$ en las democracias inestables latinoamericanas, y al $67 \%$ en las dictaduras estables latinoamericanas. Similar es la relación porcentual con respecto a las ciudades de más de 20.000 habitantes.
Mediante estos datos, Lipset establece una correlación directa entre democracia y economía.

\footnotetext{
2 No obstante la democracia moderna no es para el profesor Lipset una causal directa de los procesos industriales, sino que existen excepciones que deben contemplarse, como la de Alemania (1933-1936) en la cual los procesos económicos y democráticos no se correlacionan. (Lipset, 1988:42)

3 Para Democracias estables: Australia, Bélgica, Canadá, Dinamarca, Irlanda, Luxemburgo, Holanda, Nueva Zelanda, Noruega, Suecia, Suiza, Reino Unido, Estados Unidos; democracias inestables europeas: Albania, Austria, Bulgaria, Checoslovaquia, Finlandia, Francia, Alemania, Grecia, Hungría, Islandia, Italia, Polonia, Portugal, Rumania, España, URSS, Yugoslavia; Democracias y dictaduras inestables: Argentina, Brasil, Chile, Colombia, Costa Rica, México, Uruguay; finalmente para dictaduras estables: Bolivia, Cuba, R Dominicana, Ecuador, El salvador, Guatemala, Haití, Honduras, Nicaragua, Panamá, Paraguay, Perú, Venezuela.
} 
"Aunque hemos presentado las pruebas por separado, los diferentes aspectos del desarrollo económico - industrialización, urbanización, riqueza y educación- están tan íntimamente relacionados entre sí como para constituir un factor fundamental que posee la correlación política de la democracia" (LIPSET, 1988, p. 51).

Ahora bien, si bien los datos con los cuales se construye la correlación parecen irrefutables, la clasificación de Lipset tiene dos problemas que pueden considerarse capitales. El primero de ellos, es la necesidad de construir su modelo en base a variables mutuamente excluyentes. En ese punto, no queda muy claro el motivo por el cual el autor junta bajo la denominación Naciones Europeas y de habla Inglesa a estados de tan diferente cultura como España, Estados Unidos, Holanda y Portugal, y precisamente cual es la variable distintiva entre democracias y dictaduras inestables de naciones europeas y de habla Inglesa con respecto a democracias y dictaduras inestables de naciones latinoamericanas.

En segundo lugar, no hay indicios que lleven a presuponer cuales fueron los criterios utilizados para agrupar a las naciones en una u otra categoría. En otras palabras, ¿Qué hace a Estados Unidos más democrática que Argentina o México?, ésta parece ser una cuestión que por lo menos merece un par de líneas de justificación. "La estabilidad de cualquier democracia dada depende no solamente del desarrollo económico, sino también de la eficacia y la legitimidad de su sistema político" (idem, p. 67). En esta frase, se condensa todo el sentido su teoría, ¿pero que es realmente la eficacia?, "la eficacia significa verdadera actuación, el grado en que el sistema satisface las funciones básicas de gobierno tales como las consideran la mayoría de la población y grupos tan poderosos dentro de ella como lo son las altas finanzas o las fuerzas armadas" (ibidem).

Sin embargo, el mismo Lipset reconoce que ni legitimidad ni eficacia son inherentes a la democracia por sí. Un régimen feudal puede estar legitimado y no ser democrático como así, un modelo legitimo democrático puede no ser eficiente. El asenso social es el elemento que se introduce para explicar las diferentes revoluciones que se sucedieron en países con una democracia no estabilizada como Alemania, Francia o Italia.

El sociólogo americano, intuye que los regimenes estables según como fueron clasificados, tienen en común el hecho de haber conservado una organización basada en una monarquía constitucional. Otros estados, donde el acenso social se vio estrictamente restringido (en el pasado) como en Italia, Rusia o Alemania, dieron origen a una crisis de legitimidad que más tarde desencadenaría en una revolución. Así parece ser, como lo cuenta la historia para la revolución "bolchevique" en la Rusia de los Zares, la revuelta del Reichstag en la Alemania de Hindenburg, o la Italia de Mussolini; pero poco dice de la España Franquista (aunque siempre mantuvo su régimen monárquico), ni los Estados Unidos de América (quienes nunca aceptaron una organización orientada en la obediencia monárquica).

Aquí se suscita una paradoja (que ya hemos adelantado) y de la cual este trabajo no es ajeno. "aun cuando el sistema político es razonablemente eficaz, si en algún momento el estatus de los principales grupos conservadores se halla amenazado, o si se niega el acceso a la política a grupos que surgen en períodos decisivos, la legitimidad del sistema permanecerá siempre en tela de juicio. Por otra parte, un derrumbamiento de la eficacia, repetidamente o por un largo período, pondrá en peligro hasta la estabilidad de un sistema legitimo" (idem, p. 70).

De esa manera, las naciones que mantienen niveles altos de legitimidad y eficacia mantienen sistemas políticos estables (cuadrante A), aquellos que conservan una legitimidad alta pero disminuyen en su eficacia mantienen su régimen democrático aunque de forma inestable (cuadrante B), aquellos que se ubican con una alta eficacia y una baja legitimidad es posible dar con sistemas totalitarios - excesivamente eficaces pero ilegítimos (cuadrante C) pero cuanto éstos últimos pierden por variables exógenas su eficacia caen automáticamente (y pasan a formar parte del cuadrante $\mathrm{D}$, con escasa legitimidad y eficacia).

Este modelo, intenta explicar (de alguna u otra manera) las cuestiones que se han planteado recientemente en cuanto a la evolución histórica de los Estados Unidos, Alemania, España, Francia y Rusia con respecto a sus sistemas políticos.

¿Pero entonces que le sucedió a América Latina? Para responder esa pregunta, Lipset utiliza (al igual que Imaz) el modelo de la transculturación, 
afirmando que "la estructura social y económica que América Latina heredó de la península Ibérica le impidió seguir la dirección de las antiguas colonias inglesas, y sus repúblicas nunca desarrollaron los símbolos y el influjo de la legitimidad (idem, p. 71).

Los llamamientos a los movimientos extremistas como el de Perón (en Argentina) o Vargas (en Brasil) como así los diferentes sistemas revolucionarios antidemocráticos son una resultante a los procesos de industrialización. (Esta idea, si bien es totalmente discutible es a la que llega el autor). "Los países latinoamericanos más adelantados se asemejan actualmente a la Europa del Siglo XIX; están experimentando el desarrollo industrial, mientras sus clases trabajadoras están todavía relativamente mal organizadas en sindicatos y partidos políticos, y en sus poblaciones rurales existen todavía reductos de conservadurismo tradicional...en el grado en que existe una base social para la política extremista en esta etapa del desarrollo económico, la misma no reside en las clases medias, sino en las clases trabajadores en ascenso todavía desorganizadas, que sufren las tensiones inherentes a una rápida industrialización" (idem, p. 119).

En realidad, esto parecería ser una contradicción ya que el proceso presupone un aumento en el asenso social; y por lo tanto una mejora en la condición económica. No obstante, el aislamiento de la cual ha sido objeto la clase obrera en estos países (Argentina y Brasil) confirma la hipótesis del autor, por lo menos la tendencia a adherirse a movimientos populistas que captaron las necesidades insatisfechas de las clases bajas en su favor.

¿Se condicen los datos que interpreta Lipset con otras observaciones? ¿Cómo perciben los latinoamericanos a la democracia actualmente?

\section{IV. ¿QUÉ PIENSAN LOS LATINOAMERICANOS DE LA DEMOCRACIA?}

\section{IV.1. La realidad económica (los problemas prin-} cipales)

Cada país tiene una percepción diferente de lo que se considera su principal problema, según un listado de trece opciones, los porcentajes se distribuyen en forma totalmente diferente dependiendo del país donde se tome la muestra. Para el año 1995, el problema central del desempleo era capital para Argentina (45\%), en
Perú (31\%), Uruguay (29\%), y México (28\%). En cambio, la salud parecía ser el problema más importante para Brasil (19\%) mientras para Chile lo eran los bajos salarios (18\%) y la corrupción para Paraguay (24\%). La inflación obedece a la principal causa de preocupación en los venezolanos (13\%).

En 1996, los datos son similares. En cuanto al desempleo encabezan Argentina (43\%), Uruguay (36\%), Perú (32\%). Sin embargo, este mismo problema parece estar presente también en democracias europeas como España y en porcentajes similares (40\%).

En otros países como Bolivia, México y Venezuela el problema principal es la educación.

En 2003, el miedo al desempleo comienza a posicionarse como uno de los principales obstáculos de desarrollo que perciben los encuestados en 17 países encuestados. Esta tendencia se mantendrá incluyendo 2006 donde el $24 \%$ de los encuestados ha manifestado su idea de considerar al desempleo el problema más angustiante, seguido inmediatamente por la delincuencia con un $16 \%$.

Si se observan los datos desagregados por región se llega a la conclusión que: en Panamá, Nicaragua, Perú, Paraguay, Ecuador, Brasil y México el mayor problema que se percibe es la falta de empleo; mientras que en Argentina, Honduras, Guatemala, Venezuela, y el Salvador el principal escollo es la delincuencia.

En forma general, una comparación de 2003 a 2006 muestra una tendencia en baja en lo que respecta a la percepción del desempleo como el principal problema. En 2003 el 29\% de los encuestados lo consideraba el principal problema, este porcentaje sube al $30 \%$ en 2005 y cae al $24 \%$ para 2006. Proporcionalmente, en 2003 sólo el $8 \%$ consideraba a la delincuencia como un factor de riesgo, pero ese porcentaje en 2005 sube al $14 \%$ y en 2006 al $16 \%$.

\section{IV.2. Distribución del ingreso}

En 1996, la mayoría de los encuestados en los países consultados considera que la distribución de la riqueza es injusta. En Argentina el 66\% considera injusta la distribución, mientras que en Brasil el 78\%, Chile el 61\%, México el 78\%, Paraguay el $76 \%$, Perú el $48 \%$, Uruguay y Venezuela el $66 \%$.

En 1999, el informe de prensa respectivo ar- 
roja resultados interesantes. El 58\% de los encuestados responde que la generación de sus padres se encontraba mejor que ellos. Esto demuestra, la percepción que tienen los encuestados de las realidades económicas en las que se encuentran insertos. El restante $52 \%$ confía en que la generación de sus hijos se encontrará mejor que ellos.

Además, se le pidió que ubiquen de 1 a 10 a su generación dentro de la escala que va de los más pobres a los más ricos. La generación pasada arrojo un índice de 5.76, la generación actual 4.66, y la futura 7.66. Eso demuestra que a pesar del optimismo, existe una brecha de ciudadanos que se perciben como más cercanos a la pobreza en comparación con otras generaciones.

En 2003, en Nicaragua el $41 \%$ de los encuestados manifestó tener grandes problemas con respecto al ingreso, en Uruguay el 31\%, Salvador, $37 \%$, Guatemala $31 \%$ y Honduras $29 \%$. El informe de prensa de este mismo año señala "gran parte de las personas han sido las mismas durante generaciones, la pobreza más estructural de quienes no tienen posibilidades de movilidad social. Si bien hay segmentos que han alcanzado una movilidad social y han logrado mantenerse en un lugar más alto en la pirámide socio económico, los pobres que han quedado atrás en estos países siguen siendo las mismas familias. Ellos más que nadie, necesitan de bienes políticos de inclusión social, al mismo tiempo que un mínimo de bienes económicos para desarmar las fuentes de ingobernabilidad de la región" (LATINOBARÓMETRO, 2003, p. 8).

En 2005 y 2006, los datos demostrarán que los encuestados muestran cierto optimismo con respecto a que la economía del país mejore. Aunque, esto no signifique porcentajes altos en la satisfacción de la economía de mercado y la distribución de la riqueza. Por ejemplo, en 2005 sólo un $27 \%$ de los encuestados estaba satisfecho por la economía de mercado y como esta funcionaba (desde 2006 esto representa un aumento del 19\%). Entre aquellos países donde la satisfacción es más marcada están Venezuela (47\%), Uruguay (46\%), y Chile $(41 \%)^{4}$.

\footnotetext{
${ }^{4}$ Los aumentos progresivos en los precios del cobre y del petróleo son factores que han contribuido al alza en la mejora de las condiciones percibidas del mercado en Venezuela y Chile.
}

IV.3. Percepción de la democracia y sus instituciones

En 1995, una lectura general arroja resultados interesantes. Si bien, la mayoría de los encuestados considera a la democracia como el sistema de gobierno preferible a cualquier otra forma, los porcentajes no son homogéneos cuando se observan los datos desagregados por países. Por un lado, se encuentran países como Uruguay y Argentina donde los porcentajes de apoyo son de $80 \%$ y $76 \%$ respectivamente, pero también otros como Brasil con $41 \%$ de apoyo, México con 49\%, Paraguay, Perú y Chile con $52 \%$ y Venezuela con $60 \%$.

En Brasil por ejemplo, el 23\% definió que le daría lo mismo un régimen democrático que uno que no lo es, mientras que el $21 \%$ restante considera que en algunas circunstancias un gobierno autoritario podría ser preferible. En Chile el 25\% se manifestó que le daría lo mismo un régimen democrático o autoritario y en México ese porcentaje es del $22 \%$.

En 1996, las diferencias persisten. Mientras en países como Argentina, Uruguay, Bolivia, Perú y Venezuela el apoyo a la democracia ronda del $60 \%$ para arriba, en otros como Colombia, Chile, México, Ecuador, Brasil y Paraguay los porcentajes rondan del $60 \%$ para abajo. En Brasil todavía un $24 \%$ considera posible un gobierno autoritario, en México un 23\%, y por último Colombia el 20\%.

Comparativamente España nuestra 20 puntos por arriba de estos países con un $81 \%$ a la democracia (datos extraídos para el mismo año).

Siguiendo a los autores analizados en el marco referencial, es conveniente aclarar que una cosa es el apoyo al sistema democrático (legitimidad), el cual se ha tratado hasta aquí y otro diferente es la satisfacción de la forma en que este funciona (eficacia).

Según 1996, ante la pregunta ¿cuan satisfecho se encuentran los ciudadanos con el funcionamiento de la democracia?, se alcanza un porcentaje de satisfacción medio del $27 \%$ (considerando América del Sur y Central). Los países con un alto porcentaje de aceptación son Uruguay $(50 \%)$ y Costa Rica (50\%); En México llama la atención que sólo el $1 \%$ de los encuestados responde esa pregunta. Contrariamente, en América del Sur el $83 \%$ piensa que aún quedan cosas por hacer mientras ese porcentaje cae al $78 \%$ en Centro América. 
En 1999, los datos mostrarán cierta estabilidad en América del Sur aunque en Centroamérica aumente el porcentaje de insatisfacción, bajando en esta región del 49\% en 1997 a 39\% en 1999-2000. Costa Rica y Uruguay continúan con porcentajes de satisfacción altos del $60 \%$ aproximadamente, mientras que Venezuela pasa de un 35\% para 1998 al $55 \%$ en $1999-2000$. En Brasil, Paraguay y
Ecuador la tendencia es decreciente, de un $24 \%$ en 1998 baja a un 12\% en 1999-2000.

En 2004, el apoyo a la democracia desciende al 53\%. Asimismo, la indiferencia a un gobierno democrático o autoritario aumenta del 16\% en 1996 al $21 \%$ en 2004. El siguiente cuadro da un panorama de la evolución que ha tenido el apoyo a la democracia desde 1996 a 2004.

TABLA 2 - APOYO A LA DEMOCRACIA - EVOLUCIÓN POR PAÍS (1996-2004)

\begin{tabular}{|c|c|c|c|c|c|c|c|c|c|}
\hline PAís & 1996 & 1997 & 1998 & 2000 & 2001 & 2002 & 2003 & 2004 & 2004-1996 \\
\hline Nicaragua & 59 & 68 & 72 & 64 & 43 & 63 & 51 & 39 & -20 \\
\hline Paraguay & 59 & 44 & 51 & 48 & 35 & 45 & 40 & 39 & -20 \\
\hline Bolivia & 64 & 66 & 55 & 62 & 54 & 56 & 50 & 45 & -19 \\
\hline Perú & 63 & 60 & 63 & 64 & 62 & 57 & 52 & 45 & -18 \\
\hline Guatemala & 51 & 48 & 54 & 45 & 33 & 45 & 33 & 35 & -16 \\
\hline Colombia & 60 & 69 & 55 & 50 & 36 & 39 & 46 & 46 & -14 \\
\hline Costa Rica & 80 & 83 & 69 & 83 & 71 & 77 & 77 & 67 & -13 \\
\hline Panamá & 75 & 71 & 71 & 62 & 34 & 55 & 51 & 64 & -11 \\
\hline Brasil & 50 & 50 & 48 & 39 & 30 & 37 & 35 & 41 & -9 \\
\hline Argentina & 71 & 75 & 73 & 71 & 58 & 65 & 68 & 64 & -7 \\
\hline Ecuador & 52 & 41 & 57 & 54 & 40 & 49 & 46 & 46 & -6 \\
\hline El Salvador & 56 & 66 & 79 & 63 & 25 & 40 & 45 & 50 & -6 \\
\hline Uruguay & 80 & 86 & 80 & 84 & 79 & 78 & 78 & 78 & -2 \\
\hline México & 53 & 52 & 51 & 45 & 46 & 63 & 53 & 53 & 0 \\
\hline Chile & 54 & 61 & 53 & 57 & 45 & 50 & 51 & 57 & 3 \\
\hline Honduras & 42 & 63 & 57 & 64 & 57 & 57 & 55 & 46 & 4 \\
\hline Venezuela & 62 & 64 & 60 & 61 & 57 & 75 & 67 & 74 & 12 \\
\hline R. Dominicana & - & - & - & - & - & 75 & & 65 & $\mathrm{n} / \mathrm{a}$ \\
\hline América Latina & 61 & 62 & 62 & 60 & 48 & 56 & 53 & 53 & -8 \\
\hline
\end{tabular}

FONTE: Latinobarómetro (2004, p. 5).

NOTAS:

1. n/a: no aplicable

2. Pregunta hecha: “¿Con cuál de las siguientes frases está Ud. más de acuerdo? La democracia es preferible a cualquier otra forma de gobierno. En algunas circunstancias, un gobierno autoritario puede ser preferible a uno democrático. A la gente como uno, nos da lo mismo un régimen democrático que uno no democrático". *Aquí están sólo los resultados de la respuesta: "La democracia es preferible a cualquier otra forma de gobierno".

Los coeficientes porcentuales de variación han disminuido en 13 de 17 países, mientras que sólo se mantiene positivo en 4. Esto demuestra que el apoyo a la democracia como sistema político va en declive. En algunos casos, en forma estrepitosa como Nicaragua, Paraguay, Bolivia, y Perú. En otros, en forma moderada como Argentina, Ecuador, el Salvador. En Chile, Honduras y Venezuela el apoyo a la democracia adquiere una tendencia inversa y se observa en alza.

En una segunda evaluación el informe de prensa de 2004, muestra que al evaluar la eficacia de los civiles con respecto a los militares, la mayoría de los entrevistados dice que los militares son menos eficientes que los civiles (en 12 de 18 países). Entre los 4 países que dicen que los militares son más eficientes que los civiles se observan desigualdades económicas estructurales, Brasil, Perú, 
Guatemala y Paraguay. Asimismo, en 10 de los 18 , se superpone el orden a la pérdida de libertades (sobre todo en Centroamérica). En efecto, solamente países como Uruguay, Venezuela, Ecuador, Panamá la mayoría opina que la libertad debe primar por sobre el orden.

El informe concluye "la base del autoritarismo político en América Latina está sin dudas, en esta demanda de orden o autoritarismo social, donde la población prefiere el orden en vez de libertades. No hay que olvidarse de ello al analizar las contradicciones de la región y al analizar la demanda de mano dura, que no es otra cosa que la expresión política de esa demanda de orden que va mucho más allá de la política. Se refiere a la jerarquía piramidal, a las estructuras sociales, a la aceptación de los cambios, a la velocidad de la evolución que están influenciadas por esta importante presencia del orden en las sociedades latinoamericanas".

En Honduras el $69 \%$ prefiere más orden que libertades, en Paraguay un $65 \%$, en República Dominicana un 63\%, en Costa Rica un 56\%, en el Salvador un 54\%, en Guatemala un 53\%, en Brasil 53\%, en Argentina 50\%, y por último en Perú y México un $48 \%$.

Resultados similares muestra el grupo de países donde se considera mayoritariamente que la mano dura no le viene mal a la democracia: Paraguay (85\%), El Salvador-Guatemala-Costa Rica y Honduras (78\%), Chile (76\%), Colombia (72\%), Panamá (71\%), Perú (70\%), Argentina $(69 \%)$ entre otras.

En lo que respecta a la percepción del voto, la mayoría de los encuestados manifestaron en 1995 con referencia a sus elecciones presidenciales que las mismas eran fraudulentas (54\%) mientras el resto consideraba que habían sido limpias (37\%). En 2006, si bien la mayoría sigue considerando las elecciones como fraudulentas, el porcentaje cae al $49 \%$ conjuntamente con el alza de aquellos que las consideran comicios limpios $41 \%$. Un grupo de países (particularmente) muestran una confianza muy baja en cuanto a la legitimidad de sus elecciones: Paraguay (20\%), Ecuador (21\%), El Salvador (23\%), Honduras $(27 \%)$, Colombia $(29 \%)$, Nicaragua (30\%), Perú (32\%) y Guatemala (32\%).

Evidentemente, las instituciones en las que más confían los latinoamericanos desde 1996 a 2006 son La Iglesia y la Televisión. Esto se observa en contraposición a la confianza en las instituciones democráticas propiamente dichas tales como el Congreso, el Poder Judicial, El gobierno, los partidos políticos y la Policía. El siguiente cuadro, es más que elocuente al respecto.

TABLA 3 - SERIE DE TIEMPO - CONFIANZA EN LAS INSTITUCIONES

\begin{tabular}{|c|c|c|c|c|c|c|c|c|c|c|}
\hline INSTITUCIÓN & 1996 & 1997 & 1998 & $1999-2000$ & 2001 & 2002 & 2003 & 2004 & 2005 & 2006 \\
\hline Iglesia & 76 & 74 & 78 & 77 & 72 & 71 & 62 & 71 & 71 & 71 \\
\hline Televisión & 50 & 46 & 45 & 42 & 49 & 45 & 36 & 38 & 44 & 64 \\
\hline Presidente & - & 39 & 38 & 39 & 30 & - & 31 & 36 & 43 & 47 \\
\hline $\begin{array}{l}\text { Fuerzas } \\
\text { Armadas }\end{array}$ & 41 & 42 & 38 & 43 & 38 & 38 & 30 & 40 & 42 & 44 \\
\hline Gobierno & - & - & 28 & - & - & 25 & 24 & 30 & 36 & 43 \\
\hline $\begin{array}{l}\text { Empresas } \\
\text { grandes }\end{array}$ & - & - & - & - & 36 & 32 & 30 & 42 & - & - \\
\hline $\begin{array}{l}\text { Empresa } \\
\text { privada }\end{array}$ & - & - & - & - & - & - & - & - & 38 & 42 \\
\hline Municipalidad & - & - & - & - & 31 & 32 & - & 34 & 37 & - \\
\hline Bancos & - & - & - & - & - & 36 & 27 & 41 & 39 & - \\
\hline Policía & 30 & 36 & 32 & 29 & 30 & 33 & 29 & 37 & 37 & 37 \\
\hline $\begin{array}{l}\text { Sistema } \\
\text { Judicial }\end{array}$ & 33 & 36 & 32 & 34 & 27 & 25 & 20 & 32 & 31 & 36 \\
\hline Congreso & 27 & 36 & 27 & 28 & 24 & 23 & 17 & 24 & 28 & 27 \\
\hline $\begin{array}{l}\text { Partidos } \\
\text { políticos }\end{array}$ & 20 & 28 & 21 & 20 & 19 & 14 & 11 & 18 & 18 & 22 \\
\hline N. de casos & 18719 & 17767 & 17739 & 18038 & 18135 & 18522 & 18658 & 19607 & 20209 & 20234 \\
\hline
\end{tabular}

FONTE: Latinobarómetro (2004, p. 34; 1996-2006). 
Sin embargo, el porcentaje de personas que apunta a considerar a la Democracia como la mejor alternativa para llegar a ser un país desarrollado es particularmente significativa alcanzando porcentajes del $50 \%$ y más: El Savaldor $(86 \%)$, México (82\%), Ecuador (82\%), Colombia (82\%), Honduras (80\%), Perú (79\%), Bolivia (77\%), Brasil $(76 \%)$, Venezuela $(74 \%)$, Paraguay $(74 \%)$, Nicaragua (68\%), Chile (65\%), Argentina (65\%), Uruguay (58\%), Venezuela (48\%) entre otras.

Aquí puede verse claramente una disociación entre la figura de la democracia como sistema ideal para alcanzar un fin (enfoque estructural) y la confianza que existe en la dinámica y el accionar de las instituciones democráticas (enfoque procedimental). Esta división, se encuentra presente en la cultura de los países latinoamericanos como afirmaba el profesor de De Imaz. Pero la evidencia empírica que se ha presentado no resuelve algunas de las cuestiones que se han fijado en la introducción, sobre todo aquellas orientadas a ver como se vive la democracia en otras partes del mundo y que diferencias muestran con la América Hispana.

\section{ALGUNAS COMPARACIONES CON EURO- PA Y LOS ESTADOS UNIDOS}

Entre los porcentajes que Latinoamérica ha arrojado para con la satisfacción de la democracia, los datos de Europa Central y Oriental no parecen ser muy disímiles.

Según información de Eurobarometer 19982000, muestra en Europa Central y Oriental un porcentaje alto de encuestados que se manifiestan disconformes con respecto a la democracia. Un $60 \%$ (de los que se incluyeron en la muestra) dicen no estar contentos con la democracia como sistema político mientras sólo un $37 \%$ dicen estar satisfechos.

Si estos mismos resultados se comparan con la Europa Occidental, la escena política es totalmente diferente. En los entrevistados correspondientes a la muestra de esta región, el $62 \%$ manifestó estar satisfecho con la democracia mientras un $32 \%$ dijo estar insatisfecho.

En los Estados Unidos, según encuestas realizadas por diversas fuentes que pueden consultarse en la página Polling Report, el 58\% de los encuestados considera que la corrupción en Washington, D.C., está esparcida, contra un 39\% que la ve encriptada. Asimismo, el $61 \%$ de los encuestados se manifiesta disconforme con el rumbo que lleva los Estados Unidos mientras sólo el $30 \%$ dice estar conforme. Sobre los problemas principales que perciben los ciudadanos estadounidenses, se encuentran la situación con Irak $(59 \%)$, el terrorismo $(54 \%)$, la política sanitaria (44\%) y la economía (38\%)

En efecto, según el barómetro nacional publicadas por Gallup en USA Today, el 64\% de los encuestados considera que la situación económica está empeorando mientras que el $28 \%$ cree que está mejorando.

En relación a sus instituciones democráticas la percepción continúa siendo buena. El 61\% considera y aprueba la forma que en sus líderes democráticos se desempeñan en el Congreso mientras que el $28 \%$ los desaprueba (un $12 \%$ no sabe).

Los porcentajes parecen ser similares en la percepción del funcionamiento de la Suprema Corte de Justicia; donde en 2006 el 60\% aprueba la forma en que se desempeña esta institución contra un $32 \%$ que dice no estar de acuerdo con su desempeño. (El porcentaje de los que no están seguros es $8 \%$ ). Los mismos datos, vuelven a ser corroborados por otra encuesta llevada a cabo en el mismo año, donde el $50 \%$ aprueba a la Corte Suprema contra $30 \%$ que no lo hace. (El porcentaje de los que no están seguros es alto del $20 \%$.)

Algunas hipótesis conllevan la idea de que una de las particularidades que distingue a la democracia americana del resto, es su fuerte convicción y apoyo a sus instituciones democráticas y en la división de poderes que limita los alcances del presidencialismo. Ante la pregunta ¿Quién en Washington debería tomar las riendas de los problemas de la nación: el presidente o el congreso?, el $51 \%$ ha optado por responder el Congreso mientras que un $29 \%$ dijo el Presidente.

Sin embargo, estos datos son parcialmente correctos. Si se desagrega la información por identificación partidaria, se observa que el $65 \%$ de los republicanos apoya al presidente mientras que el 15\% al Congreso. En forma inversa, el 79\% de los demócratas apunta al congreso contra un $9 \%$ que se orienta hacia el presidente. En realidad, la responsabilidad recae sobre el presidente o el congreso según corresponde la afiliación partidaria de quien responda, y no necesariamente en la figura de la división de poderes. 


\section{CONCLUSIONES}

Más allá, de los problemas inherentes a cada región y la satisfacción que cada uno manifieste con respecto al rumbo de su país, entre la percepción de los encuestados en las muestras de los Estados Unidos y Latinoamérica parece ser claro que los primeros siguen conservando una imagen positiva en cuanto al desempeño de sus instituciones como tales en el sentido procedimental.

Por el contrario en los segundos, la percepción parece estar unida en forma estrecha con la forma en que se solucionan los problemas. Entre ellos se encuentran la delincuencia y el desempleo. En este grupo se advierte una relación directa entre la utilidad percibida del sistema político con ciertos beneficios esperados de la economía de mercado y la distribución de la riqueza.

Asimismo, la percepción que los consultados poseen sobre la eficacia de los militares parece ser más baja con respecto a los civiles. Esto se debe, en parte, a toda una historia de desaciertos por parte de los gobiernos militares en asuntos de Estado.

Si bien esta forma de vivir la democracia es una herencia ibérica, las diferentes privaciones (económicas en su mayoría) de las cuales han sido objeto las poblaciones hispanoamericanas han llevado a la idea de una fuerte disociación entre el ideal democrático y los métodos para llegar a él. (Diferencia entre la democracia en su sentido estructural y procedimental.) Por ese motivo, existen ciertas contradicciones según los datos analizados.

Lo ideal y lo real confluyen en equilibrio, son necesarios para la vida política pero cuando uno de los dos merma el otro se exacerba en forma proporcional. Es común, observar una mayor presencia del ideal cuando menores son las oportunidades de éxito. Inversamente, en grupos estables y exitosos es frecuente que los ideales comiencen a perder fuerza.

Aún cuando, en los Estados Unidos y Europa se observa mayor estabilidad democrática, la percepción de los encuestados con respecto al futuro del país -sobre todo en los Estados Unidos- es particularmente negativa. No obstante, esto no parece incidir en la percepción que ellos muestran hacia sus instituciones.
Por otro lado, cabe aclarar que en Latinoamérica se encuentra arraigada (por herencia cultural) una fuerte tradición en pensar la democracia como ideal político orientada hacia el desarrollo económico. Lo cual, no sólo confirma la evidencia recogida sino que valida las teorías de Lipset e Imaz - aunque con cierto reparo.

Así, la mayoría de los encuestados en la muestra extraída de los informes de Latino barómetro apunta a que la Democracia es un método. Pero no termina la cuestión precisamente allí, sino que es el "mejor" de los métodos para alcanzar la prosperidad y el desarrollo económico.

El funcionamiento de la democracia como sistema político es percibido en Latinoamérica de acuerdo a sus resultados. De esta forma, no es extraño encontrar porcentajes relativamente elevados de personas que manifiesta su idea de aplicar mano dura o políticas más autoritarias para ciertos problemas.

En parte, esto supone que se debe reformular la hipótesis planteada en la introducción de la siguiente manera: los latinoamericanos poseen una imagen de la democracia mayoritariamente idealizada (estructural), a diferencia de otros países donde esa percepción se hace más procedimental.

A diferencia de los objetivos que requieren ser concretados en tiempo y forma, los ideales cumplen una función ambivalente; en primer lugar, los grupos o individuos distribuyen las acciones que consideran necesarias para alcanzar la meta "idealizada".

Lejos de considerarse indiferentes, por un lado la mayoría de los latinoamericanos (encuestados) considera que la democracia es la mejor forma de desarrollarse, es decir apuntan hacia un ideal bien definido y subordinan escolásticamente los métodos para concretar el fin; empero por el otro, una tendencia antagónica se observa cuando manifiestan que es preferible superponer los métodos al ideal democrático.

Los elementos instrumentales necesarios para llevar a la práctica a la democracia están totalmente desprestigiados en América Latina. Esto se debe en parte, a su funcionamiento práctico pero más se debe a lo que se espera de ellas. En su reemplazo, se ha colocado a otras instituciones como la Iglesia Católica o la Televisión. 
Aunque estas interpretaciones parecen ser elocuentes con respecto a los datos presentados, esto trae aparejadas ciertas cuestiones que hasta ahora no han sido consideradas: Latinoamérica está lejos (como objeto de estudio) de mostrar una homogeneidad en algunos aspectos. Países tan cercanos como Argentina y Uruguay conforman en algunos temas percepciones muy diferentes, mientras que en otros casos países - tan alejados geográficamente - como Brasil y El Salvador parecen mostrar puntos de vista similares. Esto abre todo un abanico de preguntas que hacen a cómo analizar la región sin caer en generalizaciones absurdas o arbitrariedades teóricas. En realidad, presupone la necesidad de reestructurar toda la teoría sociológica y política acorde a las realidades que se vive Hispanoamérica -con sus similitudes y sus diferencias.

Maximiliano Korstanje (maxikorstanje@hotmail.com) é Mestre em Sociologia pela Universidade Católica da Argentina.

\section{REFERÊNCIAS BIBLIOGRÁFICAS}

BERNSTEIN, B. 1989. Clases, códigos y control: estudios teóricos para una Sociología del Lenguaje. Madrid : Akal.

BOBBIO, N. 1996. El futuro de la democracia. $3^{a}$ ed. Ciudad de México : Fondo de Cultura Económica.

BUCHANAN, J. 1979. Politics without Romance. IHS Journal, n. 3, p. B1-B11.

CANTRIL, H. 1941. The Psychology of Social Movement. New York: Wiley and Son.

CHAMBERS, W. \& SALISBURY, R. 1967. La democracia en la actualidad. Ciudad de México : Hispano Americana.

DAHL, R. A. 1991. La democracia y sus críticos. $5^{\mathrm{a}}$ ed. Buenos Aires : Paidós.

DIDEROT, D. \& D'ALMBERT, J. 1986. Artículos políticos de la Enciclopedia. $2^{\mathrm{a}}$ ed. Madrid : Tecnos.

DOTTI, J. E. 2000. Carl Schmitt en Argentina. Buenos Aires : Homo Sapiens.

DRYZEK, J. \& BEREJIKIAN, J. 1993. Reconstructive Democratic Theory. American Policial Science Review, Washington, D. C., v. 87 , n. 1 , p. $48-60$, Mar.

EASTON, D. 1965. A System Analysis of Political Life. New York : J. Willey.

FROMM, E. 1965. El miedo a la libertad. Buenos Aires : Paidós.

GOGUEL, F. 1953. Geographie des elections sociales de 1950-51. Revue Francaise de
Science Politique, Paris, n. 3, p. 246-270.

GOODIN, R. (comp.). 2003. Teoría del diseño institucional. Barcelona : Gedisa.

HABERMAS, J. 1981. La transformación estructural de la vida pública. Barcelona : G. Gilli.

IMAZ, J. L. 1964. Los que mandan. Buenos Aires : Eudeba.

. 1984. Sobre la identidad iberoamericana. Buenos Aires : Sudamericana.

JANOWITZ, M. \& MARVICK, D. 1953. Authoritarism and Political Behaviour. Public Opinion Quarterly, v. 17, n. 2, p. 185-201, Summer.

KELSEN, H. 2005. Teoría pura del Derecho. $6^{\mathrm{a}}$ ed. Buenos Aires : Eudeba.

LAPORTA, F J. 1989. Sobre la teoría de la democracia y el concepto de representación política : algunas propuestas para debate. Doxa, n. 6, p. 121-141. Disponible em : http:// www.cervantesvirtual.com/servlet/ SirveObras/01361620813462839088024/ cuaderno6/Doxa6_06.pdf. Acesso em : 5.ago.2007.

LATINOBARÓMETRO. 2003. La democracia y la economía. Santiago de Chile : Corporación Latinobarómetro. Disponível em : http:// www.uned.es/dcpa/Asignaturas/Intropol/ recomendaciones/Latinobarometro2003.pdf. Acesso em : 5.ago.2007.

.2004. Una década de mediciones. Santia- 
go de Chile : Corporación Latinobarómetro. Disponível em : http://ksghome.harvard.edu/ $\sim$ pnorris/Acrobat/stm $103 \% 20$ articles/ Latinbarometer2004\%20Final.pdf. Acesso em : 5.ago.2007.

LIEUWEN, E. 1960. Armas y politica en América Latina. Buenos Aires : Sur.

LIPSET, M. S. 1988. El hombre político : las bases sociales de la política. Buenos Aires : Tecnos.

MAQUIAVELO, N. 2006. El principe. $10^{\mathrm{a}}$ ed. Buenos Aires : Quadrata.

MERTON, R. K. 1965. Teoría y estructura sociales. $2^{\mathrm{a}}$ ed. Buenos Aires : Fondo de Cultura Económica.
NICHOLAS, H. 1951. British General Election of 1950. Londres : Macmillan.

SARTORI, G. 1988. Teoría de la democracia. Madrid : Alianza.

TOCQUEVILLE, A. 1993. La democracia en América. T. 2. $3^{\mathrm{a}}$ ed. Madrid : Alianza.

TOURRAINE, A. 1995. ¿Qué es la democracia? Buenos Aires : Fondo de Cultura Económica.

WEBER, M. 1999. Ensayos de Sociología contemporánea. T. 1. $3^{\mathrm{a}}$ ed. Buenos Aires : Grandes obras del Pensamiento.

WOLIN, S. 1973. Política y perspectivas: continuidad y cambio en el pensamiento político occidental. Buenos Aires : Amorrortu.

\section{OUTRAS FONTES}

ACTON INSTITUTE. s/d. Diccionario de términos claves para una sociedad libre y virtuosa. Disponível em : http://www.acton.org/es/ diccionario.htlm. Acesso em : 5.fev.2007.

EUROBAROMETER. 1998-2000. Informe de prensa. Koeln : Eurobarometer. Disponível em : http://www.observatorioelectoral.org. Acesso em : 5.fev.2007.
LATINOBARÓMETRO. 1995-2006. Informes de prensa. Santiago de Chile : Corporación Latinobarómetro. Disponible em : http:// www.latinobarometro.com. Acesso em : 5.fev.2007.

POLLING REPORT. 2006. Issues Facing the Nation. Disponível em : http:// www.pollingreport.com/issues.htm. Acesso em : 5.ago.2007. 
POLITICAL PROCESSES IN LATIN AMERICA: A PERSPECTIVE ON HOW LATIN AMERICANS VIEW DEMOCRACY

\section{Maximiliano Korstanje}

This article deals with issues around Latin American perceptions of democracy as a figure of the political order. The results we arrive at then let us engage in a brief comparison with people from the United States and Europe. The issue we study is located in the theoretical tension between democracy when taken in its more procedural or more structural senses.

KEYWORDS: democracy; Latin America; indifference. 
PROCESSUS POLITIQUES EN AMÉRIQUE LATINE: UNE PERSPECTIVE SUR LA FAÇON DE VOIR LA DÉMOCRATIE DES LATINO-AMÉRICAINS

\section{Maximiliano Korstanje}

Cet article traite des enjeux liés à la perception des latino-américains de la démocratie comme une figure d'ordre politique. Les résultats obtenus rendent possible de faire des comparaisons entre les Américains et les Européens. L'aspect étudié se situe dans la tension théorique entre démocratie dans son sens pratique et structural.

MOTS-CLÉS: démocratie; Amérique Latine; indifférence. 